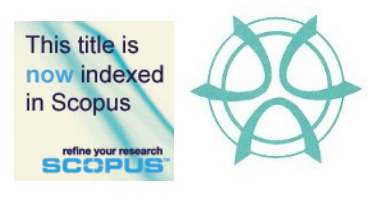

PLANNING MALAYSIA:

Journal of the Malaysian Institute of Planners

VOLUME 19 ISSUE 1 (2021), Page $25-40$

\title{
THE EFFECTIVENESS OF GOVERNMENT PROGRAMMES FOR SMALL AND MEDIUM TOURISM BUSINESSES FROM AN INSTITUTIONAL PERSPECTIVE
}

\author{
Nor Syuhada Zulkefli ${ }^{1}$, Mastura Jaafar ${ }^{2}$ \& Azizan Marzuki ${ }^{3}$ \\ ${ }^{1,}$ Faculty of Hospitality, Tourism and Wellness, \\ UNIVERSITI MALAYSIA KELANTAN \\ ${ }^{2,3}$ School of Housing, Building and Planning, \\ UNIVERSITI SANS MALAYSIA
}

\begin{abstract}
It is well-known that the tourism sector has significantly contributed to economic and social development in developing countries, including Malaysia. The government has a major influence on implementing programmes to support tourism businesses. Previous researchers have proven that the implementation process of these programmes is complex and ineffective. Therefore, this paper explored the implementation of various tourism programmes and barriers to effective implementation. Using semi-structured interviews, seven respondents were selected from government agencies at different organisational levels. The findings revealed that the main barriers are found in the government organisation itself, which are lack of collaboration among agencies, insufficient resources, and lack of skilled agencies to implement effective programmes. Besides, external factors, such as low involvement among local operators, emerged as the main barriers faced by government agencies. This paper proposes the need for the government to clearly understand the objective, the functions, and the implementation process of each tourism programme.
\end{abstract}

Keywords: Government agencies; Government Programmes; Programmes Implementation; Qualitative Approach; Perhentian Island

\footnotetext{
${ }^{1}$ Lecturer at Universiti Malaysia Kelantan Email: syuhada.z@umk.edu.my
} 
Nor Syuhada Zulkefli, Mastura Jaafar \& Azizan Marzuki

The Effectiveness of Government Programmes for Small and Medium Tourism Businesses from An

Institutional Perspective

\section{INTRODUCTION}

Within the service industry, tourism has become a dynamic sector and is considered the most rapidly growing activity in the world's economy (Charoensukmongkol, 2016). Like other developing countries, Malaysia's tourism sector is a sub-sector in the services sector that contributes $13.7 \%$ to the country's gross domestic product (GDP) (Department of Statistics, 2016). Small and medium enterprises (SMEs) appear to be the most dominant sector, with $61.9 \%$ of business establishments in the services sector (Department of Statistics, 2016). It has been acknowledged that the government plays a significant role in creating an enabling conducive environment for SMEs (Charoensukmongkol, 2016). The government major influence to implement programmes to develop SMEs in developing countries have increased significantly over the past decade, as seen by several researchers (Doh \& Kim, 2014, Lawrence \& Weber, 2014; Obeng \& Blundel, 2015). Doh and Kim (2014) referred to government programmes as part of government policy implementation. The implementation of programmes is essential to support the competitiveness faced by tourism business and industries (Doh \& Kim, 2014, Obeng \& Blundel, 2015; Wang and Ap, 2013).

The government is a major stakeholder in tourism development; however, tourism planning has been impeded by the government's shortcomings in implementing tourism programmes for SMEs (Ismet \& Abuhljeelah, 2016; Khalid \& Saad, 2015). Unclear authorities and responsibilities of each division and lack of supervision and monitoring at the local level are among the obstacles faced by the government in implementing the policies and programmes (Wang \& Ap, 2013; Ismet \& Abuhljeelah, 2016). Scholars from Malaysia also highlighted several issues related to programmes implementation, namely inadequate funding, poor coordination, frequent government change, and the unclear role of tourism stakeholders (Marzuki \& Hay, 2013; Khalid \& Saad, 2015; Islam, Noh, Yew \& Noh, 2013). These obstacles hinder the development process and affect the effectiveness of government programmes implementation.

However, those studies have omitted how the government programmes implementation has been carried out and the effectiveness of the programme's implementation. Specifically, in Malaysia, several authors have explored the role of government in supporting SMEs development in a quantitative way (Awang, Aziz \& Samsudin, 2015) and the impact of government programmes on SMEs sustainability (Jamaludin \& Yusof, 2017). Nevertheless, there has been less attention given to the process and implementation of effective government programmes for tourism businesses. Besides, only a handful of studies have probed into the context of Malaysia's tourism islands, especially from the government stance. 
Island tourism plays a crucial role in maintaining tourism income in Malaysia (Jamaludin \& Yusof, 2017). Perhentian Island is a popular and preferred location for small- and medium-sized hotels. According to Mohamad and Mohamed (2018), this island is one of the premier tourist destinations in Terengganu and a famous spot with steady growth in the number of tourist arrivals to this island. Besides that, the main reason for choosing Perhentian Island is that activities and income for local businesses are highly dependent on tourist activities. However, the businesses here have begun facing difficulties, such as seasonality due to monsoon season, shortage of qualified staff, insufficient supplementary facilities and services, poor service quality, and high employee turnover (Mohamad \& Mohamed, 2018; Jamaludin \& Yusof, 2017). Looking at these constraints, government programmes could provide good input to strengthen the tourism businesses on this island. Hence, this paper explored the various types of government programmes implemented and the barriers behind effective implementation of government programmes in Perhentian Island.

\section{LITERATURE REVIEW}

\section{Implementation of Government Programmes}

In most developed and developing countries, government programmes have been used to support or stimulate SMEs (Cancino, Bonilla, \& Vergara, 2015). Hoang (2016) defined government programmes as an approach used by the government to improve, promote, and provide SMEs training to progress, and the programmes are developed based on government agendas. Given the importance of SMEs to the national economies, most of these initiatives are specifically designed to suit the needs of SMEs (Blackburn, 2016; Hoang, 2016). Government programmes for SMEs consist of two types; financial and non-financial. Financial programmes refer to the financial help of various institutions and organisations for starting new SME businesses. There are many accesses to funding programmes, such as grants, loans, credit guarantees and subsidies (Doh \& Kim, 2014; Hoang, 2016). Access to finance remains at the top of the list of obstacles faced by SMEs in developing countries (Beck, 2013; Doh \& Kim, 2014). Nonfinancial programmes refer to support that excludes money, such as business advice, training programmes, and marketing programmes (Hoang, 2016; Sambajee \& Dhomun, 2015).

The last few years have witnessed the increasing number of contributions that prompt studies to investigate government business support programs' effects. Most researchers have used survey evidence to assess government programmes' use and perceived effectiveness (Cancino et al., 2015; Doh \& Kim, 2014; Klonowski, 2010). In Malaysia, Ismail and Othman (2014) concluded that government services programmes had a positive impact on business growth among its SMEs. 
Nor Syuhada Zulkefli, Mastura Jaafar \& Azizan Marzuki

The Effectiveness of Government Programmes for Small and Medium Tourism Businesses from An Institutional Perspective

Although there is a positive impact on government programmes for SMEs, some SMEs have recorded to face difficulties in receiving government programmes. Several researchers have highlighted the lack of government support for SMEs and underutilisation of existing business support services (Cancino et al., 2015), as well as complicated and lengthy legislation process (Sambajee \& Dhomun, 2015). In Malaysia, Hung, Effendi, Talib and Rani (2011) revealed that most of the existing government programmes had not been completely implemented due to the complicated application procedures, limited allocation of resources, and some activities that were only meant for new enterprises. Awang et al. (2015) found that most small businesses faced difficulties in sourcing funds from the government or financial institutions due to the high-risk business located at the islands.

\section{Barriers behind Effective Implementation of Tourism Programmes}

In numerous surveys concerning entrepreneurs, government programmes have been mentioned as a critical factor to business success (Crick \& Lindsay, 2015; Doh \& Kim, 2014). Nevertheless, a number of reasons have been listed to explain the failures of government programmes to support the development of SMEs. Among these factors are poor quality of support service, poor government service, and limited resources (Sambajee \& Dhomun, 2016); inefficient government organisation (Wang \& Ap, 2013); as well as overlapping of powers, poor coordination between tourism agencies, lack of experience among agencies, limited available programmes provided, and unclear role of tourism stakeholders (Ismet \& Abuhjeeleh, 2016).

According to Doh and Kim (2014), the federal government's funding in developing countries may be limited and is allocated for the development of certain activities. Keppel et al. (2013) also claimed that the infrastructure development in Kiribati Island could not be implemented due to an ongoing land ownership issue and inadequate funding allocated from the federal government. Besides that, lack of understanding about local businesses caused the government's failure to provide suitable programmes and relevant information for the local operators in Malaysia (Chen \& Chen, 2017; Salehudin et al., 2015). The issue of lack of inter-organisation collaboration is associated with ineffective governance to develop tourism destination. This is because of overlapping areas of responsibilities, failures in making the decision, and lack of sufficient knowledge among government agencies (Khalid \& Saad, 2015; Marzuki \& Hay, 2013; Salehudin et al., 2013). Besides that, Waligo et al. (2013) found that the involvement of local operators appeared to be the most important participation in government programmes. Most local operators were reluctant to involve in tourism development due to many processes and rules that need to be adhered to (Komppula, 2014; Doh \& Kim, 2014) and irrelevant government programmes 
provided for their needs (Obeng \& Blundel, 2015). Salehudin et al. (2015) found that the lack of information from government agencies was a common reason for the owners not participating in government programmes.

\section{Island Tourism in SMEs}

The tourism industry has reached the island destination with numerous primary attractions, such as marine resources, beaches, and panoramas (Nasir et al., 2017). Many islands worldwide have penetrated the dynamic international competition to attract tourists and gain a global tourism market position. Despite its importance, many islands seem to face several issues regarding the sustenance of their natural environment and local businesses (Mohamad \& Mohamed, 2018). Some researchers have revealed that it is common for island tourism to experience chronic issues, such as a seasonal business, low occupancy rates, transportation difficulties, insufficient supplementary facilities and services, poor service quality, and high turnover (Awang et al., 2015; Sambajee \& Dhomun, 2016; Mohamad \& Mohamed, 2018). These issues demand attention from the formal institution to assist and to support the survivability of SMEs.

\section{RESEARCH METHODOLOGY}

\section{Study Area}

Perhentian Island is one of the coral reef islands situated on the east coast of Peninsular Malaysia. This island was gazetted as Marine Parks Area in 1994 under the Malaysian Fisheries Act 985 (amended 1993) to conserve and protect its marine flora and fauna from being damaged by fishing and other human activities. The Perhentian Archipelago consists of two main islands; Perhentian Kecil (small) and Perhentian Besar (large), covering a land area of 1,392.1 hectares. The Marine Park management of Perhentian Island is under the Marine Park of Department Malaysia (MPRM) that belongs to the Federal government jurisdiction. Meanwhile, land on the island belongs to the State government that decides on all land-based on development activities. The local authority (Besut District Council) is responsible for providing facilities, infrastructure, and amenities to the local community, operators, and tourists. Most of the tourism businesses in Perhentian Island are dominated by SMEs. In the year 2016, 47 small and medium accommodation businesses were established and operated in Perhentian Island (Besut District Council, 2017).

\section{Research Approach}

In order to gain detailed information on the government programmes implemented and their barriers behind the implementation, the exploration of this issue required an interview. This study used the qualitative approach via face-toface semi-structured interviews (Silverman, 2007). This method aims to get a 
Nor Syuhada Zulkefli, Mastura Jaafar \& Azizan Marzuki

The Effectiveness of Government Programmes for Small and Medium Tourism Businesses from An

Institutional Perspective

first-hand explanation of various government programmes implemented and the barriers to implement that government programmes in Perhentian Island. This approach was viewed as equally appropriate, enabling the researcher to obtain indepth views and experiences of knowledgeable individuals who are intricately involved with programmes implementation.

Purposive sampling was performed to select the best possible respondents who can provide rich information related to the case (Silverman, 2007). The respondents were profiled beforehand to ensure that they had had sufficient project experience (Silverman, 2007). The respondents' selection was based on the concept of information power related to 1) their knowledge, 2) their involvement, and 3) their experience on policies and programmes implemented in Perhentian Island. The interviews were conducted with seven respondents (R1R7) from different government organisation levels. The respondents represented the Federal government, as well as State and local authorities. In order to ensure data saturation, the interview was continued until the respondents provided no new information.

Prior to the interview, permission was sought from the stakeholders for their consent to be interviewed. The interviews were then audio-taped to ensure accuracy, and no information was missed out. Table 1 presents the background of the study respondents.

Table 1: Details of respondents

\begin{tabular}{|c|c|c|c|}
\hline Respondent & Position & Agencies & $\begin{array}{c}\text { Working } \\
\text { experience }\end{array}$ \\
\hline $\mathrm{R} 1$ & $\begin{array}{l}\text { Administrative } \\
\text { Officer }\end{array}$ & $\begin{array}{l}\text { Ministry of Tourism and } \\
\text { Culture (MOTAC) }\end{array}$ & 6 years \\
\hline $\mathrm{R} 2$ & Assistant Officer & Department of Marine Park & 4 years \\
\hline R3 & Senior officer & \multirow{2}{*}{ UPEN } & 23 years \\
\hline $\mathrm{R} 4$ & Technical officer & & 20 years \\
\hline R5 & Assistant manager & \multirow{3}{*}{ Besut District Council } & 6 years \\
\hline R6 & Technical officer & & 15 years \\
\hline R7 & Senior Officer & & 22 years \\
\hline
\end{tabular}

\section{Data Analyses}

The gathered data were analysed by using thematic content analysis. Content analysis is a "research technique for making applicable and valid inferences from data in their context" (Krippendorff, 1980, p. 21). The thematic content analysis employed in this study entails locating and clustering texts into applicable themes. This is a process of data condensation, where thematic categorisation results from constant interpretation and comparison of data. A process of detailing the substance of the interview was performed by sorting the respondents' feedback into several content-related categories. 


\section{RESEARCH FINDINGS}

\section{The implementation of government programmes}

This section describes the findings gathered from semi-structured interviews and relies heavily on the actual narrations of the respondents. The results revealed five types of programmes implemented by the government in Perhentian Island, which are 1) funding, 2) human resources, 3) marketing, 4) consultation, and 5) infrastructure, as shown in Table 2.

Table 2: Detailed of programmes implemented in Perhentian Island

\begin{tabular}{|c|c|c|}
\hline $\begin{array}{c}\text { Types of } \\
\text { programmes }\end{array}$ & $\begin{array}{l}\text { Agencies to } \\
\text { implement }\end{array}$ & Type of each programmes implemented \\
\hline Funding & $\begin{array}{l}\text { MOTAC in } \\
\text { collaboration } \\
\text { with other } \\
\text { agencies }\end{array}$ & $\begin{array}{l}\text { tourism fund, tourism special fund, tourism } \\
\text { infrastructure fund, budget accommodation funds, } \\
\text { tax incentive }\end{array}$ \\
\hline $\begin{array}{l}\text { Human } \\
\text { resources }\end{array}$ & $\begin{array}{l}\text { MOTAC; local } \\
\text { authority; } \\
\text { Marine park } \\
\text { department }\end{array}$ & $\begin{array}{l}\text { - Skills programmes, communication skill, } \\
\text { management, and others for local operator } \\
\text { - tourist boat operating course, environmental } \\
\text { awareness workshop, and tourist guide workshop }\end{array}$ \\
\hline Marketing & $\begin{array}{l}\text { MOTAC; state } \\
\text { agencies } \\
\text { (UPEN); local } \\
\text { authority }\end{array}$ & $\begin{array}{l}\text { Main events- Visit Beautiful Terengganu (VBT) } \\
\text { 2017, Visit Terengganu in } 2016 \text { and } 2013 \\
\text { Activities - windsurfing challenge, long beach } \\
\text { international activities, marine exhibition, seminar } \\
\text { conversation of marine life, }\end{array}$ \\
\hline Consultation & MOTAC & Consultancy programmes \\
\hline Infrastructure & Local authority & $\begin{array}{l}\text { upgrading and improving the jetty, providing } \\
\text { infrastructure and facilities }\end{array}$ \\
\hline
\end{tabular}

\section{Funding}

Funding programmes are essential programmes implemented by the government for local operators in the tourism sector. MOTAC is responsible for providing several funding programmes for the local operators to develop their businesses in collaboration with several agencies.

"At the state level, we also provide tourism grant for tourism operators who are actively involved in MOTAC and state programmes and events..." (G3)

The results found that these funding programmes were open to all local operators, especially those registered and actively involved with MOTAC and local authority. The implementation of funding programmes involved several procedures and processes that must be adhered to by the local operators to ensure 
Nor Syuhada Zulkefli, Mastura Jaafar \& Azizan Marzuki

The Effectiveness of Government Programmes for Small and Medium Tourism Businesses from An

Institutional Perspective

only eligible operators receive funding. Respondents G1 and G6 explained the procedures involved;

"There are a few stages for local operators to apply the funding programmes, which are 1) they should register their business with the MOTAC and Besut District Council (local authority); 2) they need to fill several forms and submit supporting documents; and 3) they must pay a processing fee of RM200 for each funding application."

Respondent G1 further described the process involved. The application result would not be released not more than six months after submission. The process would take a long time upon glitches or problems.

\section{Human resources}

Several training programmes were provided by the federal government (MOTAC) and the local authority to enhance the operators' skills and knowledge. One respondent (G1) claimed, "Federal government focused on the collaboration with tourism NGOs and training institutions to provide various trainings for local operators". He also admitted,

“...MOTAC had collaborated with several agencies to provide training programmes... for instance, they have collaborated with SME cooperation to provide training in business skills and knowledge".

The findings found that MOTAC had collaborated with other institutions, such as an Industrial Training Institute, UiTM, and Terengganu State Skills Development Centre, to assist operators. Meanwhile, respondent G2 also mentioned that the Marine Park Department collaborated with MOTAC to provide several training programmes related to tourist guide courses. He added:

"These courses are compulsory for local operators before they can obtain license to bring the tourists from the Marine Park Department... before that, local operators must register with us..."

\section{Marketing}

MOTAC and UPEN departments are responsible for organising marketing programmes to develop the tourism industry and increase tourist arrivals. These programmes were organised to support the aim of the state government to develop Perhentian Island into a premier ecotourism destination. The implementation of these events and programmes had encouraged the involvement of local operators 
to join and organise state events and programmes. Respondent G5, who had experience in handling local operators, explained,

"Prior to the event, we would send an invitation letter to the local operators via email, fax, or direct communication through local authorities... sometimes we personally go to the site with local authorities to get cooperation from the local people and operators in coordinating the event".

In line with this, respondent G3 disclosed his own strategy to attract the local operators involved in state event, saying, "actually we provided some incentives to attract the local operators to get involved in our programmes...". The local operators used these incentives to prepare in terms of cleaning up and improving resort maintenance, providing better services and promotion of activities to attract tourist arrivals.

\section{Consultation}

These programmes fell under the MOTAC's responsibility. The purpose of consultancy programmes is to help local operators solve their business problems, share ideas, and provide opinions for business development. Respondent G1 revealed;

"This programme is compulsory for local operators, who had registered their businesses with MOTAC because we need to monitor their operation... this service refers to free consultation for operators to share their problems and gain more knowledge about business management..."

Respondent G1 explained the three steps that need to be adhered to by the local operators, which are 1) Local operators need to register their businesses with the local authority (Besut District Council) and MOTAC to obtain consultation programmes; 2) Local operators need to attend meetings every three months at MOTAC office until their businesses are matured, normally after one year of business operation; and 3) Local operators need to submit their business report to monitor the progress of the business.

\section{Infrastructure}

Infrastructure is the main component that stimulates the tourism business and the image of tourism destinations. In this study, the provision of supporting infrastructure for the tourism sector is mainly under the local authorities' responsibility. This role is stipulated in the role of the local authority in Malaysia Planning Act 171, supported by state and federal governments, in terms of 
Nor Syuhada Zulkefli, Mastura Jaafar \& Azizan Marzuki

The Effectiveness of Government Programmes for Small and Medium Tourism Businesses from An

Institutional Perspective

funding allocation. To that extent, respondent G1 explained that "Federal government had allocated more budget for infrastructure development and improvement of public facilities for each of tourism development area..."

On the other hand, the local authority focused on providing and improving basic physical infrastructure development to support the local operators in their businesses in Perhentian Island. Respondent G7 claimed that "Most of the infrastructure development in Perhentian Island involved upgrading and improving the jetty at mainland, Kuala Besut, including the three main jetties situated at Perhentian Kecil and Perhentian Besar".

Barriers behind the effective implementation of government programmes As part of each stage of the interview process, the respondents were asked to list barriers that they perceived that hinder effective implementation of government programmes. The results of the responses are classified into four central themes.

\section{Limited resources}

Several issues related to funding were revealed during the interviews. The Federal Government allocated the budget for infrastructure development. Due to limited budget, respondent G5 mentioned: "they did not have enough money when we proposed to improve facilities and utilities at Perhentian Island for local community and tourist".

The implementation of tourism infrastructure in Perhentian Island had faced difficulties due to land ownership matters. Most of the lands are owned by the local people and external investors. These investors had bought the land from the local people with higher prices to develop tourism businesses.

"We cannot develop or improve the infrastructure and accommodation premises to become a proper building on this island because huge pieces of lands belong to private companies and local people". (G3)

"These investors are not giving their cooperation to develop their lands...even though their lands have been abandoned without any development..." (G6)

The respondents also claimed that that location is a barrier to implementing better infrastructure for local businesses. Respondent G1 stressed, "In a way, the problem here is the location. Perhentian Island has limited transportation and public facilities to organise huge programmes for local operators... so, most of the programmes are organised in the mainland..." 
PLANNING MALAYSIA

Journal of the Malaysia Institute of Planners (2021)

\section{Lack of collaboration among agencies}

Lack of inter-collaboration between state agencies and the local authority was mentioned in the in-depth interviews. Several reasons were cited for the lack of collaboration between them. Respondent G5 mentioned that they only communicated with the local authorities when issues are raised. He mentioned;

"We only communicate when we want to get information, for example, report on the registration of local operators, current building condition, and tourism business in Perhentian Island... the local authority will just provide data for us..."

Respondent G7 argued that there was no regular meeting with the local authority about tourism planning and asserted, "the state government does not involve us in the decision-making process... so that is a reason why the collaboration between us is poor...". He added, “... Most tourism development decisions on Perhentian Island were approved by the state without any meeting and coordinating with local authority..."

Due to this issue with the state government, respondent G6 revealed, "we don't have enough manpower to monitor and control the development of Perhentian Island, although this island is under the local authority administration...”.

\section{Low involvement among operators}

Most of the respondents claimed that local operators play a crucial role in the tourism industry. However, another barrier mentioned refers to the involvement of local operators. Several respondents raised issues related to operators, as follows:

"It is difficult to gain support from local operators because they are less aware and are not really willing to get involved with us... only 39\% (11 out 28) of the operators have responded positively towards our programmes...". (G3)

"Most of the operators had problems getting involved in our programmes due to their commitment, not understanding our intention and internal problems..." (G4)

Besides, several respondents found it difficult to cope with and involve the local operators in government programmes. Interviewees highlighted that local operators need to change their mindset, not only in terms of business changes but also to accept the new development agenda in Perhentian Island for business growth. Respondent G3 said, "Local operators are not interested with 
Nor Syuhada Zulkefli, Mastura Jaafar \& Azizan Marzuki

The Effectiveness of Government Programmes for Small and Medium Tourism Businesses from An

Institutional Perspective

new development and they are not ready to accept the new development and regulation in Perhentian Island...'

Respondent G4 alluded that despite organising numerous programmes, implementation is failed because "almost 40\% (19 out of 47 resorts) had not registered their businesses with MOTAC and local authority...so it is difficult to get cooperation from them to get involved in government programmes and events..." Another respondent clarified;

"Sometimes, other problems hinder the government to develop and implement the programmes and tourism events in that island, such as social problems, unsystematic business operations, and improper premise building to cater to the tourist demands..."

This situation resulted in low involvement among local operators in government programmes and hence, the reasons why certain programmes cannot be implemented.

\section{Lack of experience and experts' agencies}

Lack of appropriate in-house skills and knowledge within government agencies emerged as a major concern, including business management, operations and skills to communicate with local operators. Several respondents, such as G1, G3, G5, and G7, highlighted similar problems in the organisation. Respondent G4 commented that "Actually, we had problems managing the local operators' activities and operations due to insufficient staff experience in managing the business..."

Similarly, respondent G6 disclosed, "Yes...one of our problems is knowledge on tourism business operation and competition among them..." Respondent G1 added;

"I admit that this issue happened because we can't provide more information based on market demand... sometimes we are lacking experience in handling local operators for certain training programmes..."

Based on these findings, five programmes were implemented for local operators in Perhentian Island. However, their implementation seemed ineffective due to several barriers faced by government agencies. This study has highlighted the four main barriers that should be addressed by government agencies to support tourism businesses. 
PLANNING MALAYSIA

Journal of the Malaysia Institute of Planners (2021)

\section{DISCUSSION AND CONCLUSION}

Table 3: Summary of the barrier behind effective implementation

\begin{tabular}{|c|c|}
\hline Barrier behind effective implementation & Type of programmes \\
\hline 1. $\quad$ Limited resources & $\begin{array}{ll}- & \text { Infrastructure } \\
- & \text { Funding }\end{array}$ \\
\hline 2. Lack of collaboration among agencies & Marketing \\
\hline 3. Low involvement among operators & Human resources \\
\hline 4. Lack of experience and experts' agencies & $\begin{array}{ll}- & \text { Human resources } \\
- & \text { Consultation }\end{array}$ \\
\hline
\end{tabular}

The following discussion reveals the findings of the present study. This study has proven that the government plays an important role in supporting tourism businesses in Perhentian Island. Five government programmes have been implemented, namely funding, human resources, marketing, consultancy, and infrastructure programmes to support the local operators. Government programmes have functioned as an important back-up for local operators seeking help to start and grow their businesses. This result is supported in prior studies (Awang et al., 2015; Ismail \& Othman, 2014). The government has placed strong support in developing the tourism sector, as Hadiyati (2015) claimed that government programmes emerge as a key instrument to unlock SMEs' economic growth in developing countries.

The present study has identified two main barriers that influenced government programmes' effective implementation, which are barriers of government organisations (limited resources, lack of inter-collaboration, and lack of experience and experts' agencies) and local operator (low involvement from local operators) that related with programmes implemented as show in Table 3. Collaboration between government organisations has been identified as the key to effective tourism programmes implementation (Marzuki \& Hay, 2013). Therefore, the capability of local authority to collaborate with other organisation (state government) is important in achieving effective implementation of programmes for local operators.

Besides, it is important to highlight the limited role of the local authority in tourism development. Tourism is seen as the main responsibility of the state government, while local authority only deals with operational matters, such as specific activity arrangement that requires approval from the local authority. The findings are similar to several studies pertaining to tourism destinations in Malaysia (Khalid \& Saad, 2015; Marzuki \& Hay, 2013). This study found that most development and improvement of infrastructure and public facilities had been unsuccessful due to financial constraint allocated for tourism development at the local level. 
Nor Syuhada Zulkefli, Mastura Jaafar \& Azizan Marzuki

The Effectiveness of Government Programmes for Small and Medium Tourism Businesses from An Institutional Perspective

Apart from barriers from the government organisation, another barrier behind this issue derived from local operators. Almost all respondents claimed similar barriers, which is low involvement among local operators in government programmes. This indicates that most local operators in Perhentian Island were not interested and refused to cooperate with the government, especially on training and events. This issue is a huge challenge for the government to implement effective programmes for them. Low involvement from the local operators is a major obstacle to implement effective programmes (Waligo et al., 2013; Salehudin et al. 2015).

This study has provided valuable insight into the government implementation of tourism programmes. The approach revealed the interactions between different government organisations' tiers to implement effective tourism programmes in Malaysia. There is a need for the policymakers to relook on the role played by each government agency to stimulate future tourism businesses. The effective implementation of government programmes through a clear mission, better programme coordination, and high working spirit among staff should strengthen the inter-organisation ties. The togetherness spirit of these government agencies in arranging tourism activities or events or programmes will significantly impact the local business operators.

Although this study has focused on the tourism development in Perhentian Island, other tourism destinations in Malaysia may face similar issues due to a similar governance structure. This study has several limitations, such as a small number of interviews with a limited group of stakeholders that only focused on government officers. The tourism industry involves a wide range of stakeholders with different roles. Therefore, future researchers can gather views from different stakeholders on related matters pertaining to the tourism industry. The use of multiple case studies will enhance the reliability and generalisability of the research findings.

\section{REFERENCES}

Awang, K., W., Aziz, A., Y, \& Samdin, Z. (2015). The growth of Micro, Small and Medium-sized Hotel Enterprises: The hotelierse perspectives. Journal of Technology Management and Business, 2(1), 302-317.

Bager, T. E., Jensen, K. W., Nielsen, P. S., \& Larsen, T. A. (2015). Enrollment of SME managers to growth-oriented training programs. International Journal of Entrepreneurial Behavior \& Research, 21(4), 578-599.

Beck, T. (2013). Bank financing for SMEs-lessons from the literature. National Institute Economic Review, 225(1), 23-38.

Besut District Council (2017). Besut Disctrict Council Strategic Plan. Retrieved January 2017 from http://mdb.terengganu.gov.my/en/mdb/resources/publications

Blackburn, R. A. (2016). Government, SMEs and entrepreneurship development: Policy, practice and challenges: Routledge. 
Cancino, C. A., Bonilla, C. A., \& Vergara, M. (2015). The impact of government support programs for the development of businesses in Chile. Management Decision, 53(8), 1736-1754.

Charoensukmongkol, P. (2016). The interconnections between bribery, political network, government supports, and their consequences on the export performance of small and medium enterprises in Thailand. Journal of International Entrepreneurship, 14(2), 259-276.

Chen, C.-F., \& Chen, F.-S. (2010). Experience quality, perceived value, satisfaction and behavioral intentions for heritage tourists. Tourism Management, 31(1), 29-35.

Crick, D., \& Lindsay, V. (2015). Service and service-intensive New Zealand internationalizing SMEs. Marketing Intelligence \& Planning, 33(3), 366-393.

Department of Statistics, Malaysia (2016). Retrieved April 2017 from https://www.dosm.gov.my/v1/

Dredge, D. and Jenkins, J. M. 2007. Tourism planning and policy, Milton: John Wiley.

Doh, S., \& Kim, B. (2014). Government support for SME innovations in the regional industries: The case of government financial support program in South Korea. Research Policy, 43(9), 1557-1569.

Hadiyati, E. (2015). Marketing and government policy on MSMEs in Indonesian: a theoretical framework and empirical study. International Journal of Business and Management, 10(2), 128-141.

Hoang, Q. N. (2016). Legislative policy in support of Vietnam SMEs: Analysis and Propositions. International Journal of Economics and Finance, 8(2), 226-233.

Hung, D. K. M., Effendi, A. A., Talib, L. S. A., \& Rani, N. A. B. A. (2011). A preliminary study of top SMEs in Malaysia: Key success factor vs government support program. Journal of Global Business and Economics, 2(1), 48-58.

Islam, G. M. N., Noh, K. M., Yew, T. S., \& Noh, A. F. M. (2013). Assessing environmental damage to marine protected area: a case of Perhentian Marine Park in Malaysia. Journal of Agricultural Science, 5(8), 132-141.

Ismail, R., \& Othman, N. A. (2014). The effectiveness of government-support programmes toward business growth. Journal of Technology Management and Technopreneurship, 2(2), 41-52.

Ismet, E., \& Abuhjeeleh, M. (2016). The analysis of tourism policies by different governments and their potential implementation in North Cyprus Economy. Journal of Political Sciences \& Public Affairs, 4(4), 2-13.

Jamaludin, M., \& Yusof, Z. B. (2017). Challenges faced by MSICs Operators. Asian Journal of Behavioural Studies, 2(5), 1-9.

Keppel, G., Morrison, C., Watling, D., and Tuiwawa, M.V., (2012). Conservation in tropical Pacific Island countries: why most current approaches are failing. Conservation Letters, 5, 256-265.

Khalid, S.-N. A., \& Saad, N. H. M. (2015). Tourism planning and stakeholders' engagement: the case of Penang Island. Problems and Perspectives in Management, 13(2), 269-276.

Klonowski, D. (2010). The effectiveness of government-sponsored programmes in supporting the SME sector in Poland. Post-Communist Economies, 22(2), 229245 . 
Nor Syuhada Zulkefli, Mastura Jaafar \& Azizan Marzuki

The Effectiveness of Government Programmes for Small and Medium Tourism Businesses from An

Institutional Perspective

Komppula, R. (2014). The role of individual entrepreneurs in the development of competitiveness for a rural tourism destination: A case study. Tourism Management, 40, 361-371.

Krippendorff, K. (1980). Content Analysis: An Introduction to Its Methodology, Sage: London.

Lawrence, A. T., \& Weber, J. (2014). Business and society: Stakeholders, ethics, public policy: Tata McGraw-Hill Education: San Francisco.

Marzuki, A., \& Hay, I. (2013). Towards a Public Participation Framework in Tourism Planning. Tourism Planning \& Development, 10(4), 494-512.

Mohamad, D., \& Mohamed, B. (2018). Acceptance towards tourism development: The case of Perhentian Island. Planning Malaysia, Journal of the Malaysian Institute of Planners, 16(4), 117 - 129

Nasir, N. M., Ibrahim, M., Mahamod, L. H., \& Othman, R. (2017). Challenges to implement carrying capacity framework: A case study of Pulau Perhentian Marine Park institutional framework. Planning Malaysia, 15(1), 163-168.

Obeng, B. A., \& Blundel, R. K. (2015). Evaluating Enterprise Policy Interventions in Africa: A Critical Review of Ghanaian Small Business Support Services. Journal of Small Business Management, 53(2), 416-435.

Phulkerd, S., Sacks, G., Vandevijvere, S., Worsley, A., and Lawrence, M. (2017). Barriers and potential facilitators to the implementation of government policies on front-of-pack food labeling and restriction of unhealthy food advertising in Thailand. Food Policy, 71, 101-110.

Sambajee, P., \& Dhomun, M. Z. A. (2015). Government and SMEs in the Maldives and Mauritius. International Journal of Entrepreneurial Behavior \& Research, 21(6), 778-795.

Set, K. (2014). Exploring the internet adoption on Tourism Small and Medium Enterprises (TSMEs) in Malaysia. The Journal of Technology Management and Technopreneurship (JTMT), 2(1), 71-84.

Silverman, D. (2006). Interpreting Qualitative Data (2001.) London, Thousand Oaks, New Delhi: Sage Publications.

Waligo, V. M., Clarke, J., and Hawkins, R. (2013). Implementing sustainable tourism: A multi-stakeholder involvement management framework. Tourism Management, $36,342-353$.

Wang, D., \& Ap, J. (2013). Factors affecting tourism policy implementation: A conceptual framework and a case study in China. Tourism Management, 36, 221223.

Received: $2^{\text {nd }}$ January 2021. Accepted: $11^{\text {th }}$ March 2021 